\title{
Internet Voting for Expatriates: The Swiss Case
}

\author{
Micha Germann \\ Centre for Democracy Studies Aarau (ZDA) at the University of Zurich, Centre for Comparative and International Studies at \\ ETH Zurich, micha.germann@zda.uzh.ch \\ Uwe Serdült
}

Centre for Democracy Studies Aarau (ZDA) at the University of Zurich, uwe.serdult@zda.uzh.ch

\begin{abstract}
In 2008 the first Swiss canton introduced internet voting for expatriates, complementing the trials involving residents initiated back in 2003. More cantons soon followed, and as of this writing, expatriates from 12 out of the 26 cantons can vote online. This paper focuses on the second phase in the Swiss i-voting roll-out involving expatriates. We address three questions at the core of the internet voting research agenda. First, the popularity question: to what extent do expatriates make use of the new online voting channel? Second, the 'who' question: what is the profile of the typical expatriate $i$-voter? Finally, the turnout question: did the extension of internet voting to expatriates have an effect on electoral mobilisation? Our findings indicate that the online channel is very popular among expatriates, both when compared to other trials in Switzerland and internationally. Leaving aside i-voting's comparatively high popularity, familiar patterns seem to replicate in the expatriate trials. Expatriate $i$-voters tend to be young, male, and there is some evidence of an upper-class bias. Thus, use of the online channel by expatriates seems also driven by the digital divide. Finally, similarly to the residents' trials, we find some evidence that $i$-voting does not affect electoral mobilisation.
\end{abstract}

Keywords: Internet voting, electronic voting, online voting, e-voting, expatriates, Swiss abroad.

Acknowledgement: We thank Fernando Mendez, Jonathan Wheatley, Maja Harris, panel participants at the $14^{\text {th }}$ Conference for eDemocracy and Open Government (CeDEM), four anonymous reviewers and the editors for helpful comments on earlier versions of this paper. All remaining errors are our own. The authors gratefully acknowledge funding through the E-Democracy (edc) project. Replication files are made available on http://www.ivotingproject.com/ upon publication.

B y now, Estonia and Switzerland can be considered the two leading internet voting countries - if for somewhat different reasons. Whereas Estonia is the first and, thus far, only country to have fully generalised online voting (Alvarez et al., 2009), Switzerland boasts the highest number of online voting trials. Unlike in Estonia however, the Swiss internet voting roll-out has remained piecemeal and at an experimental stage, far from full generalisation (Mendez, 2010; Mendez \& Serdült, 2014). Switzerland's record number of i-voting trials is owed largely to its unrivalled high number of referendum votes (Serdült, 2014).

Nevertheless, the Swiss i-voting roll-out has been continuously evolving. Historically, it can be split into two phases: a first involving trials in three pilot cantons (2003-2007), and a second extending internet voting to many Swiss expatriates (2008-). A third phase is already being planned, involving further local trials. In this paper, we focus on the second phase involving expatriates, thus extending and updating our earlier reviews (Germann et al. 2014; Serdült 2010). Specifically, we address three questions, all at the core of the internet voting research agenda. First, the question of i-voting's popularity. Drawing on freshly collected data that documents the use of the online channel in Switzerland's i-voting trials, we explore the popularity of internet voting among expatriates. To put things into perspective, we compare our findings with the trials involving Swiss residents and make some references to the international experience. Second, we address the 'who' question: what is the profile of the typical expatriate i-voter? The introduction of internet 
voting has been accompanied by fears that i-voting might cater primarily for the resource-rich and thus favour the already privileged. A number of studies found empirical support for this contention, but few looked at the expatriate case. We extend the focus to this segment of voters by discussing the existing evidence and conducting a novel inquiry into the expatriate i-voter's profile using survey data from Switzerland's 2011 federal elections. Finally, we investigate the turnout question: did the extension of internet voting to expatriates have an effect on electoral mobilisation? Existing studies - at least the more sophisticated ones - have generally found that i-voting did not affect electoral turnout. But none have yet looked at the expatriate case (apart from the suggestive evidence reported by Lutz, 2012). Drawing on registration rate data and a difference-in-differences design, we conduct the first study of i-voting's mobilisation effect on expatriates.

Opportunities for research on i-voting are increasingly limited. Against earlier cyber-optimism, the majority of countries that experimented with i-voting in the early 2000s have now abandoned the idea, including the United Kingdom, France and the United States (Kersting \& Baldersheim, 2004; Mendez, 2010; Mendez \& Serdült, 2014; Trechsel \& Mendez, 2005). Recently, Norway also stopped its programme after two technically successful pilots in 2011 and 2013. Trials continue, for instance, in Canada, Australia and of course Estonia (Pammett \& Goodman, 2013), but apart from the latter they remain restricted to the local and sub-national level. This should make the lessons that can be drawn from Switzerland's expatriate trials all the more valuable, especially as more countries may eventually rediscover their appetite for bringing elections to the digital world.

The paper is structured as follows. The first section gives a brief overview of Switzerland's ivoting roll-out. The second section addresses the popularity of the online channel among expatriates. Sections three and four, in turn, investigate the profile of expatriate internet voters and i-voting's mobilisation effect. The conclusion sums up the main findings and provides a short outlook of future developments in Switzerland's i-voting roll-out.

\section{A Short History of I-voting in Switzerland}

In Switzerland, similarly to other countries, ideas of digitalising elections and referendum votes began to flourish in the late 1990s. In addition to the general cyber enthusiasm prevalent at the time, internet voting profited from Switzerland's positive experience with the earlier generalisation of postal voting, another form of remote voting. It did not take postal voting long to become the Swiss' preferred voting method. Today, regularly more than 90 per cent of votes are submitted by mail. There are even some indications that postal voting raises turnout (Lüchinger et al., 2007). Accordingly, there was hope that i-voting would be quickly accepted and boost the notoriously low Swiss turnout rates, especially among the young. Furthermore, internet voting has obvious advantages for vote counting, an inherently attractive feature for a country with the number of (referendum) votes Switzerland has.

The first parliamentary motions related to e-government and internet voting were submitted around the turn of the millennium. Soon after, first steps were taken towards implementation. Similarly to postal voting (see Lüchinger et al., 2007; Mendez, 2010), the Swiss internet voting rollout has followed a step-by-step, piecemeal kind of logic, involving extensive tests before a possible generalisation (which, after more than a decade of testing, is still a long way off). Moreover, the Swiss roll-out has been strongly shaped by the country's highly decentralised structure (Mendez, 2010; Mendez \& Serdült, 2014; Driza-Maurer, 2013). The federal government's role has remained limited to that of an agenda setter and facilitator, while implementation has been left to the cantons which hold the primary responsibility for the organisation of elections. A peculiar result of this decentralised roll-out is that Switzerland features not one, but three internet voting systems: three cantons volunteered for pilot trials - Geneva, Neuchâtel and Zurich - and each developed its own i-voting solution. Two of the three solutions - the Geneva and Zurich models - are in effect rather similar, with one of the more significant differences being that while Geneva's system is hosted by 
Table 1: Overview of the internet voting roll-out to expatriates (federal votes)

\begin{tabular}{|c|c|c|c|c|c|c|c|c|c|c|c|c|c|}
\hline & $\mathrm{NE}$ & GE & ZH & BS & FR & GR & SG & so & AG & LU & SH & TG & BE \\
\hline 01.06 .2008 & $v$ & & & & & & & & & & & & \\
\hline 30.11 .2008 & $v$ & & & & & & & & & & & & \\
\hline 08.02 .2009 & $\checkmark$ & & & & & & & & & & & & \\
\hline 17.05 .2009 & $v$ & & & & & & & & & & & & \\
\hline 27.09 .2009 & $\checkmark$ & $v$ & & & & & & & & & & & \\
\hline 29.11 .2009 & $\checkmark$ & $v$ & & $v$ & & & & & & & & & \\
\hline 07.03 .2010 & $v$ & $v$ & & $v$ & & & & & & & & & \\
\hline 26.09 .2010 & $v$ & $v$ & $v$ & $v$ & $(\boldsymbol{V})$ & $(\boldsymbol{N})$ & $\checkmark$ & $(\boldsymbol{V})$ & & & & & \\
\hline 28.11 .2010 & $\checkmark$ & $\checkmark$ & $\checkmark$ & $v$ & $(\boldsymbol{V})$ & $(\boldsymbol{N})$ & $v$ & $v$ & $v$ & $v$ & $v$ & $v$ & \\
\hline 13.02.2011 & $v$ & $v$ & $v$ & $v$ & $(\boldsymbol{V})$ & $(\boldsymbol{V})$ & $v$ & $v$ & $v$ & $v$ & $v$ & $v$ & \\
\hline 23.10 .2011 & & & & $v$ & & $v$ & $v$ & & $\checkmark$ & & & & \\
\hline 11.03 .2012 & $v$ & $\checkmark$ & & 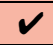 & $(\boldsymbol{V})$ & 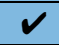 & $v$ & $v$ & $v$ & $v$ & $v$ & $\checkmark$ & $(\boldsymbol{V})$ \\
\hline 17.06 .2012 & $v$ & 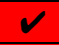 & & $V$ & $(\boldsymbol{V})$ & $V$ & $v$ & $v$ & $v$ & $v$ & $v$ & $v$ & $V$ \\
\hline 23.09 .2012 & $V$ & $\nu$ & & $V$ & $v$ & $V$ & $v$ & $v$ & $V$ & $v$ & $v$ & $v$ & $v$ \\
\hline 25.11 .2012 & $\checkmark$ & $\checkmark$ & & $v$ & $v$ & $v$ & $v$ & $v$ & $v$ & $v$ & $v$ & $v$ & $v$ \\
\hline 03.03 .2013 & $v$ & $\checkmark$ & & $v$ & $v$ & $v$ & $v$ & & $\checkmark$ & $v$ & $v$ & $v$ & $v$ \\
\hline 09.06 .2013 & $v$ & $v$ & & $v$ & $v$ & $v$ & $v$ & $v$ & $v$ & $v$ & $v$ & $v$ & $(\boldsymbol{V})$ \\
\hline 22.09 .2013 & $v$ & $v$ & & $v$ & $v$ & $v$ & $v$ & $v$ & $v$ & $v$ & $v$ & $v$ & $v$ \\
\hline 24.11 .2013 & $v$ & $v$ & & $v$ & $v$ & $v$ & $v$ & $v$ & $v$ & $v$ & $v$ & $v$ & $(\boldsymbol{V})$ \\
\hline 09.02 .2014 & $\checkmark$ & $v$ & & $v$ & $v$ & & $v$ & $v$ & $\checkmark$ & $v$ & $v$ & $v$ & $v$ \\
\hline 18.05.2014 & $v$ & $v$ & & $v$ & $v$ & $v$ & $v$ & $v$ & $v$ & $v$ & $v$ & $v$ & $v$ \\
\hline
\end{tabular}

Note: Ticks indicate that a canton offered internet voting to its Swiss abroad. In some cases, $i$-voting was available to expatriates who are registered in selected municipalities only; if so, the tick is in brackets. For technical and/or legal reasons, $i$-voting cannot be offered in a series of cantons if there are simultaneous elections and referendum votes. Thus, $i$ voting was available in only four cantons in the 2011 federal elections, for instance. Also note that before 2014, $i$-voting was restricted to those Swiss abroad who resided in an EU member state, in a state that had ratified the Wassenaar Treaty or in one of the European microstates. Green denotes usage of the Neuchâtel internet voting system, red usage of the Geneva system and blue usage of the Zurich system, with the three pilot cantons in darker colours. NE stands for Neuchâtel, GE for Geneva, ZH for Zurich, BS for Basel-City, FR for Fribourg, GR for Grisons, SG for St. Gallen, SO for Solothurn, AG for Argovia, LU for Lucerne, SH for Schaffhausen, TG for Thurgau and BE for Berne.

the canton itself, Zurich outsourced operation to a private company. The Neuchâtel model, however, is rather different. Neuchâtel's i-voting solution is integrated into a comprehensive egovernment portal in which citizens cannot only vote but also file their tax returns or order a license plate for their car, among other things. Critically, citizens who want to vote online must first sign up to the e-government portal as a whole, which requires showing up in person at an office of the municipality. In contrast, the Geneva and Zurich models do not require registration; citizens are simply mailed the log in details which allow them to cast their vote online prior to every election or referendum vote.

Switzerland's first ever binding internet vote took place in a small municipality in the canton of Geneva in 2003. More municipalities were subsequently included in the trials. In 2004 i-voting was for the first time available in a federal-level vote. The cantons of Neuchâtel and Zurich joined the trials in 2005 (Gerlach \& Gasser, 2009). Since then, numerous and largely successful trials have been conducted in the three pilot cantons. This does not mean that the roll-out has been smooth or without problems. Zurich experienced technical problems with the interface between the i-voting solution and the electronic election management system, causing it to put a temporary halt to its programme in 2011 that is ongoing at the time of writing. Geneva had problems too, but here they were more political in nature. Security concerns and perceptions of potential electoral losses nurtured opposition against i-voting, causing Geneva to suspend its programme between 2005 and 2008 (Mendez, 2010). 
Initially, the Swiss i-voting roll-out was restricted to Swiss residents. This changed in 2008 when Neuchâtel extended i-voting to its expatriates, thus initiating the second phase of the Swiss roll-out that is the focus of this paper. Expatriates are an obvious target group for i-voting, in particular because postal voting is associated with manifold problems related to postal delivery (Driza-Maurer et al., 2012). Unsurprisingly, the Organisation of the Swiss Abroad (OSA) has become one of $\mathrm{i}-$ voting's most vocal advocates. But the extension was also linked to strategic considerations. In theory, expatriates make up a sizeable 10 per cent of the Swiss electorate. Yet only a tiny minority actually participates in elections and referendums. The small numbers make concerns about security less salient. Moreover, the almost total lack of media attention further adds to the expatriates being the perfect test subjects. Finally, the expatriates' strong interest in internet voting led to expectations that they may more readily adopt the online channel. This, it was hoped, would help to create a positive story that may eventually spill over to the domestic debate, thus clearing the way for a general introduction of i-voting.

After Neuchâtel took the lead in 2008 and extended i-voting to its expatriates, other cantons soon followed suit. Geneva first offered online voting to its expatriates in 2009. The remaining pilot canton, Zurich, did so in 2010, shortly before it halted its programme (in 2011). Critically, the expatriate trials have not remained limited to the pilot cantons. In 2009, Basel-City became the first non-pilot canton to implement an internet voting programme targeted exclusively at its Swiss abroad. Within less than two years, nine additional non-pilot cantons followed Basel's lead (see Table 1).

In principle, the newcomer cantons were free to implement their own i-voting solutions. However, for financial reasons their strategy has been to form hosting co-operations with one of the pilot cantons. Two models have emerged (see Figure 1). A total of seven cantons decided to cooperate with the canton of Zurich in the form of a 'consortium'. After Zurich dropped out in 2011, the canton of Argovia took over responsibility and has since managed the consortium, which continues to use the Zurich system. The remaining three newcomer cantons chose to cooperate with the canton of Geneva. No canton has yet opted to co-operate with Neuchâtel, mainly due to the latter's peculiar setup which integrates i-voting into a larger e-government portal.

\section{Popularity of the Online Voting Channel}

How many voters make use of the opportunity to vote online is more than a technicality. There are high economic, organisational and all-too-often political costs associated with the introduction (and continuation) of $\mathrm{i}$-voting. Thus, the sustainability of $\mathrm{i}$-voting hinges also on its popularity. Moreover, usage rates are of interest from a more academic perspective. What determines the popularity of the online channel? What will the future look like? Will internet voting replace traditional forms of voting?

This section attempts to answer some of these questions. It will gauge the popularity of i-voting among Swiss voters based on a freshly collected data set and with a focus on the recent extension to expatriates. After a short description of the data we focus on the recent roll-out of i-voting to Switzerland's expatriates. We then compare the expatriate situation with the trials involving Swiss residents, including some references to the international experience. We conclude with a short discussion.

\subsection{Data}

The data set we exploit in this section tracks the share of voters who used the online channel in i-voting trials up until June 2014. For better comparability between trials in different cantons we have only included federal-level votes (both referendums and the 2011 elections), thus leaving out sub-national votes. Trials involving Swiss residents and trials involving Swiss abroad are listed separately. This allows us to compare variation in popularity between residents and expatriates. 


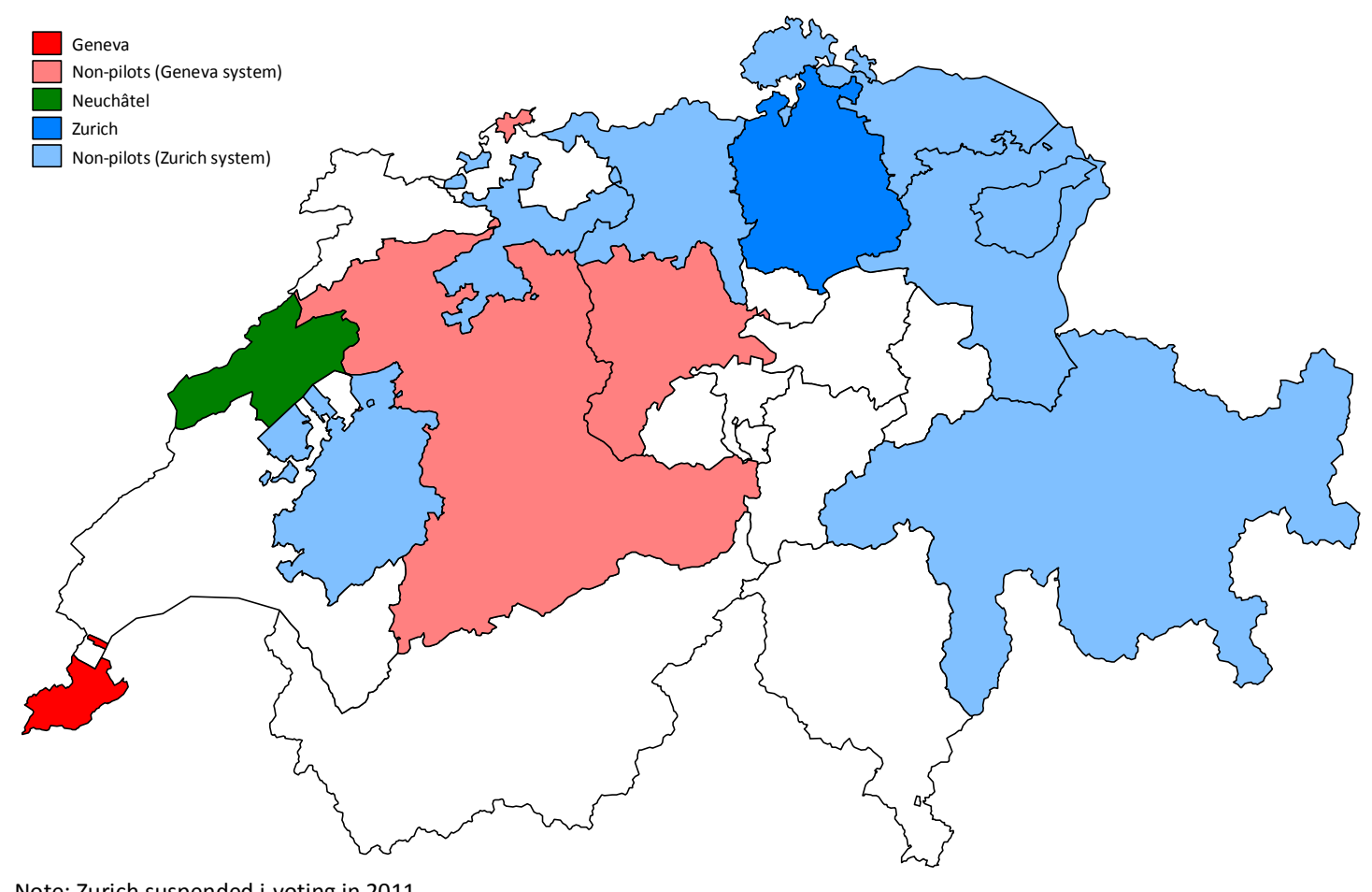

Note: Zurich suspended i-voting in 2011.

Figure 1: I-voting in Swiss cantons

Obtaining such highly disaggregated electoral data can be tricky, especially in Switzerland where the electoral administration is strongly decentralised and the different administrative layers have different practices in the maintenance of electoral records. Fortunately, this is less of a concern for the trials involving residents. The only major caveat here is that Neuchâtel's figures have a small bias until mid-2013. To safeguard the secrecy of the ballot, Neuchâtel discards much of the disaggregated data we need following every vote. Since June 2013, Neuchâtel has provided us with the necessary figures before they are deleted. Prior to June 2013, however, Neuchâtel's figures include not only Swiss residents, but also expatriates (from 2008 onwards) and in some cases even foreigners. ${ }^{1}$ However, since foreigner and expatriate votes in combination make up less than 10 per cent of all votes, Neuchâtel's figures still give a fair indication of usage among Swiss residents. ${ }^{2}$

Problems with the expatriate trials are more numerous. First, there is incomplete coverage. Four cantons - Grisons, Schaffhausen, Solothurn and Zurich - do not separately record expatriate and Swiss resident votes, which makes it impossible to know the precentage of expatriates who voted online. For a fifth canton, Neuchâtel, we only dispose of data on expatriate usage from June 2013 onwards (see above). Still, our data set covers 108 out of the 166 expatriate i-voting trials listed in Table 1 and includes data on trials in nine out of the 13 cantons which have experimented with online voting for expatriates. ${ }^{3}$ Critically however, there are problems with some of the figures: prior

\footnotetext{
${ }^{1}$ Neuchâtel is among the few cantons which lets foreigners vote in sub-national matters. Thus, Neuchâtel's figures include foreigners when there was a simultaneous vote at the cantonal or municipal level.

${ }^{2}$ Another, smaller caveat is that we needed to exclude one of Zurich's districts from the calculation of the residential ivoter share in three trials. Zurich recorded the expatriate votes in a district which also includes residential voters. This makes it impossible to disentangle usage among expatriates and residents in the three trials where expatriates were allowed to i-vote.

${ }^{3}$ For miscellaneous reasons, data from three further expatriate trials (the November 2009 and March 2010 trials in Geneva as well as the March 2012 trial in Fribourg) is missing.
} 
to 2014 the data of five cantons has a downward bias (Argovia, Lucerne, Neuchâtel, St. Gallen and Thurgau). This is due to the rule that countries which do not allow the exchange of encrypted data were excluded from the i-voting roll-out until the end of 2013. ${ }^{4}$ The five mentioned cantons do not record the votes by country of residence. Hence their figures include some voters who did not have the possibility to cast their vote online. By implication the figures underestimate the share of voters who used the online channel since not all expatriate voters included in the figure were actually able to do so. This is not overly dramatic given that the overwhelming majority of Swiss abroad reside in those parts of the world where i-voting has always been possible (almost $90 \%$ ). But it has to be noted that until the end of 2013, the figures of the cantons of Argovia, Lucerne, Neuchâtel, St. Gallen, and Thurgau come with some caveats.

\subsection{Usage Rates in the Expatriate Trials}

In the first step, we focus on the expatriate trials. Figure 2 plots the online voting rate in various cantons. The figures are annualised for better interpretation. A first important observation concerns the high popularity of i-voting among expatriates. Generally between 40 and 60 per cent of all expatriate voters used the online channel and in some cases the rate is even higher. With consistently less than ten per cent i-voters, Neuchâtel is the only stark deviation from the general pattern. This can be explained through Neuchâtel being the only canton which requires potential ivoters to sign up in person for a comprehensive e-government portal. The extra burden seems to result in much lower usage. Apart from Neuchâtel, Geneva also scores lower than the others, even if it clearly outpaces Neuchâtel. This is most likely due to the large number of citizens who live just across the border in France to escape Geneva's tense housing market. Expatriates in neighbouring countries have fewer problems with postal voting and thus fewer incentives to vote online, a point to which we return below. Finally, Lucerne also tends to score lower, but this appears to be due to measurement problems: the difference largely vanishes in 2014, the only year in which Lucerne's figures are not downward biased (see the data discussion).

A closer look at the longitudinal pattern leads to two more observations. First, the online channel has tended to gain popularity over time, with an average annual increase of approximately two percentage points. This remains true even when one takes into account that the big increases in 2014 in Argovia, Lucerne, St. Gallen and Thurgau are to a great deal due to under-reporting in previous years. Second, if we discount the spike in 2014 that is likely due to measurement problems, the upward trend appears to bottom out in many cantons (e.g. Basel-City, Geneva, Lucerne, St. Gallen and Thurgau). However, it is probably too early to tell whether the upward trend will indeed come to an end, not least because there is an obvious counter-example (Argovia).

\subsection{Comparison with the Residents' Trials}

How do the expatriate trials compare with the i-voting roll-out for Swiss residents (see Figure 3 )? To begin with, there is a striking similarity: the i-voter rate is again lowest in the one canton that features a pre-registration system - Neuchâtel. At the same time, there are two significant differences. First, the figures in the cantons without a pre-registration system (Geneva and Zurich) range between 15 and 25 per cent, far from the 40 to 60 percent rates we saw in the expatriate trials. Notably, i-voting experiments in Estonia and Canada yielded similar rates (Mendez \& Serdült, 2014; Mendez et al., 2014; Goodman, 2014). Hence, i-voting enjoys comparatively high popularity

\footnotetext{
${ }^{4}$ Thus, i-voting was restricted to expatriates from countries which signed the Wassenaar Treaty and some European microstates. The Wassenaar Treaty regulates data encryption, among other things.
} 


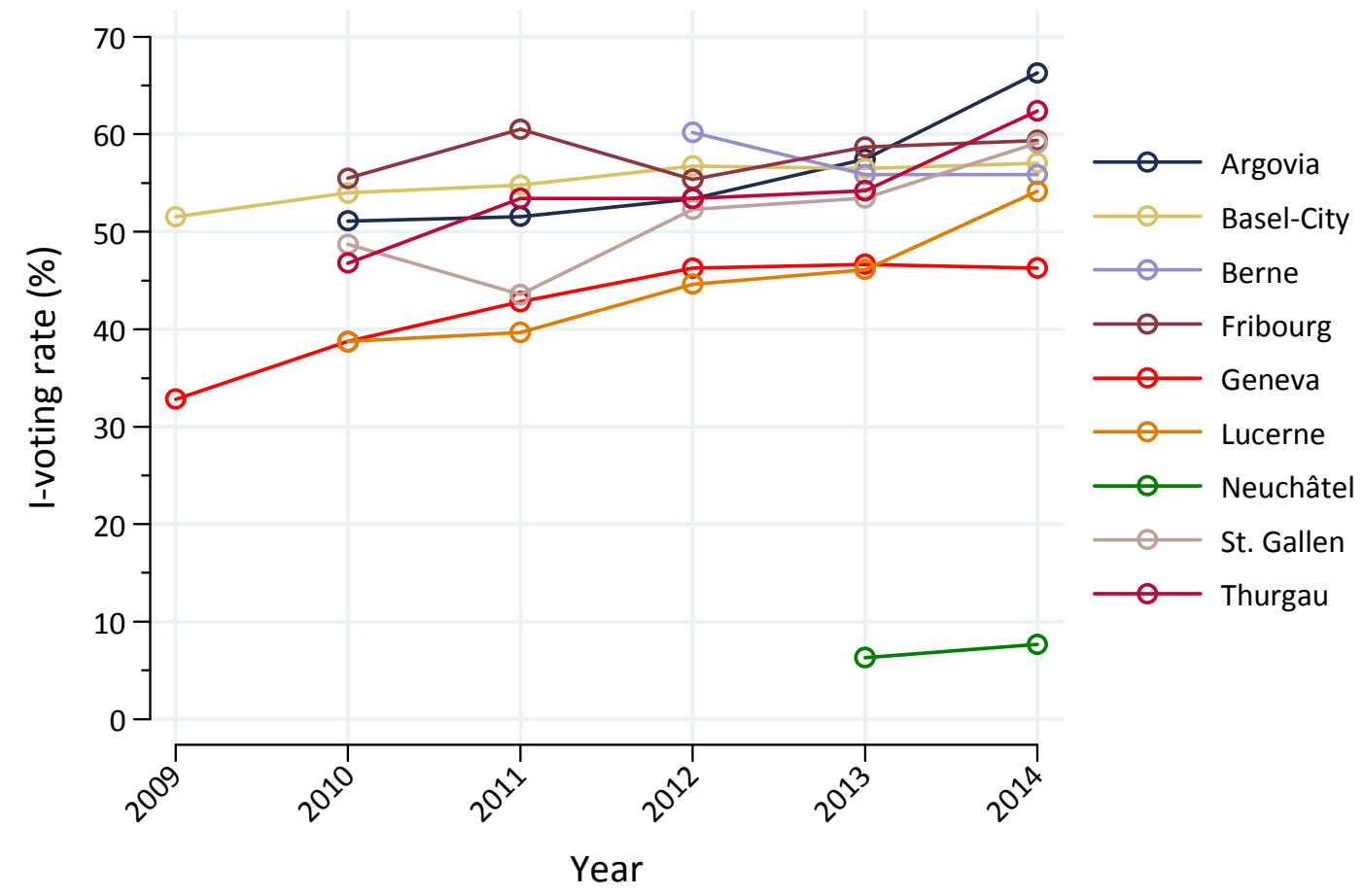

Figure 2: Popularity of the online channel among expatriate voters

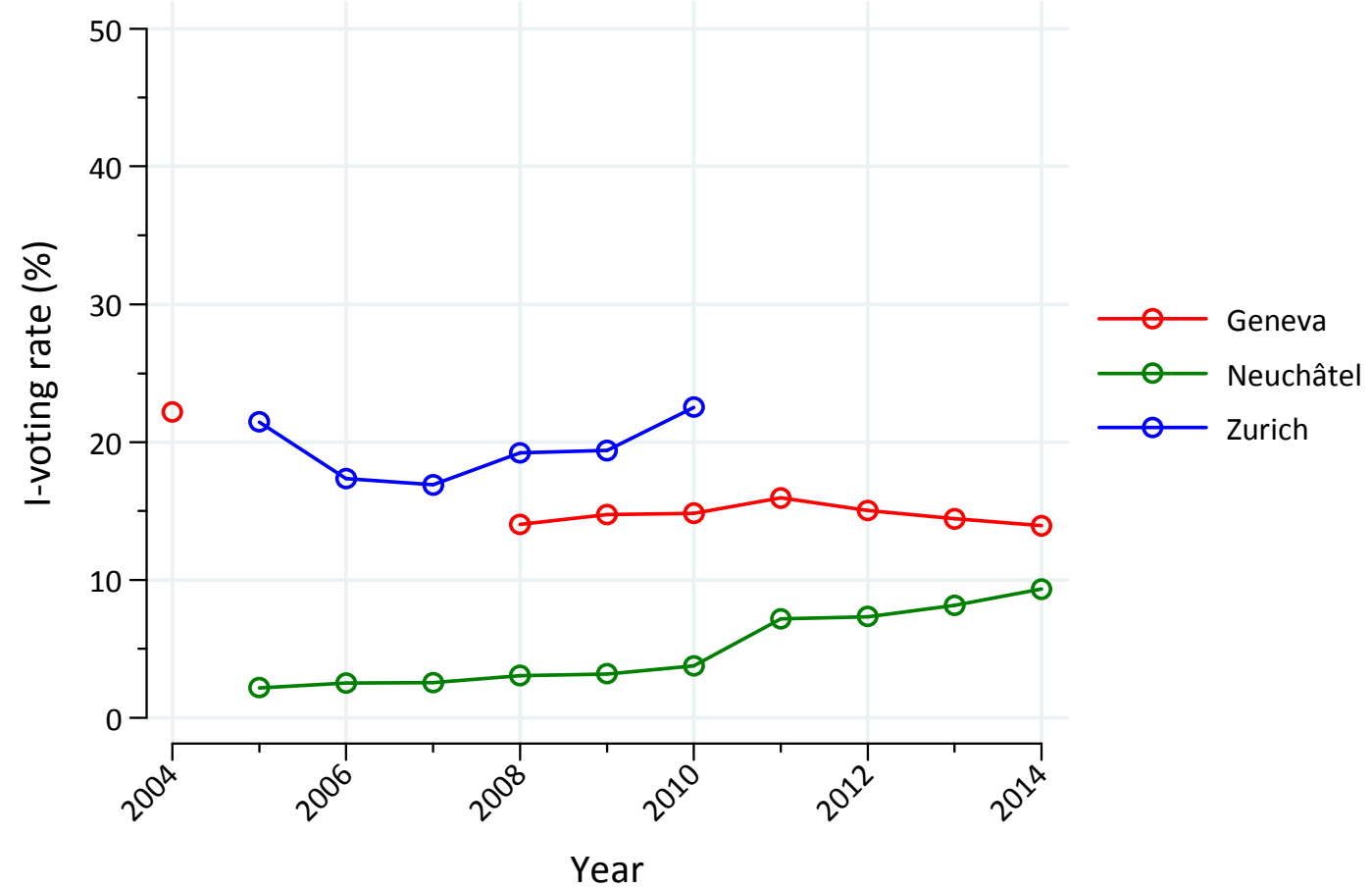

Figure 3: Popularity of the online channel among residential voters 
among Swiss expatriates, both if compared to its' popularity among Swiss residents and from an international perspective. This finding should not surprise us, given the online channel's disproportionate attraction for expatriates.

Second, contrary to the expatriate scenario, there is a general upward trend in only one case, Neuchâtel (Neuchâtel's rate remains relatively low despite the upward trend). Conversely, both Geneva and Zurich feature a drop of up to 10 percentage points after the first few trials, suggesting a novelty effect whereby a significant number of internet voters revert to their traditional method of voting after testing the online channel (Mendez and Serdült, 2014). Interestingly, usage rates recovered in Zurich (before the programme was stopped), while the downward trend seems to have continued in Geneva. Importantly, no such novelty effect appears present in the expatriate case. We have to be careful with micro-level inferences based on macro-level data (given the looming ecological fallacy), but this seems to suggest that expatriates are more loyal to the online channel.

\subsection{Discussion}

Our investigation into the popularity of the online voting channel suggests two main conclusions. First, the expatriates' high interest in internet voting is reflected in comparatively high usage rates. Up to six out of 10 expatriate voters chose the online channel in the Swiss trials, thus easily topping usage rates in the Swiss trials involving residents as well as in trials in countries like Estonia or Canada. The only major exception is the one canton with an i-voting solution that requires citizens to sign up in person; the additional cost implied decreases usage rates dramatically, both among expatriates and Swiss residents.

Second, i-voting's popularity has tended to increase over the years among expatriates. A further increase seems likely, even if there are signs that the popularity growth is slowing down. If growth does eventually stop, usage rates can be expected to stabilise at a high level since expatriates seem quite loyal to the online channel. This contrasts with the residents' trials, where usage rates tended to drop after the first few trials, suggesting a novelty effect whereby voters try the online channel a few times and then revert back to their traditional method of voting.

\section{Profiling the Expatriate Internet Voter}

A central concern associated with i-voting is that it might disproportionately benefit the already privileged. Parting from a digital divide logic (Norris, 2001), i-voting is likely to be used by the resource-rich: it is the better educated and higher earners who have the resources to buy computers and link them to the internet as well as the necessary education and skills. If we add one of the core arguments associated with i-voting - that it will increase turnout (see the next section) - there is thus a danger that i-voting may increase the representational gap between rich and poor (Alvarez \& Nagler, 2001).

Searching for empirical answers, a considerable amount of scholarly work has investigated the profile of i-voters. Notably, the profile does not necessarily tell us something about representational bias. Disproportionate use of the online channel among certain social groups does not automatically imply that these groups have also been (disproportionately) mobilised. But knowing who uses the internet to vote and whether this is driven by the digital divide is arguably interesting in and of itself, not least since it tells us something about who profits from the money spent on this voting reform.

Many of the studies that investigated the profile of i-voters focus on the two leading i-voting countries, Estonia (e.g. Alvarez et al. 2009; Trechsel \& Vassil, 2011) and Switzerland (e.g. Christin \& Trechsel, 2005; Sciarini et al., 2013; Serdült \& Trechsel, 2006). Others cover some of the less well-known experiments with the online channel in the US (e.g. Alvarez \& Nagler, 2001), the UK (Henry, 2003), Canada (e.g. Goodman, 2014), and Norway (e.g. Bergh \& Christensen, 2012). While some differences have emerged, the existing studies suggest a more or less coherent 
picture (for a recent review, see Portenier et al., 2014). Unsurprisingly, among the most consistent findings is that internet voters tend to be young. What may come as a surprise, however, is that it tends to be not the very youngest who make use of the online channel most often, but rather the 25 to 50 years cohort, suggesting a curvilinear relation between age and i-voting. Furthermore, ivoters tend to have higher incomes and be better educated. Lastly, males tend to be overrepresented among i-voters, but this finding fails to achieve statistical significance in a number of studies and is thus somewhat ambiguous.

In addition to these basic socio-economic variables, some studies looked at political concepts such as political interest or trust in political institutions. Here, findings are more mixed, with most studies finding no significant differences between i-voters and non-i-voters. Only occasionally do scholars find, for instance, that internet voters tend to be better informed about politics (Sciarini et al., 2013) or that i-voters are more politically interested and active (Trechsel \& Vassil, 2011). A very consistent finding, however, is that most socio-economic and political differences disappear as soon as one accounts for factors such as computer skills, internet affinity and trust in the i-voting mechanism as well as in the internet more generally. In other words, it does not appear to be age, gender or social status as such that make people vote over the internet, but rather the higher frequency of internet access and usage among the young(ish), better educated, better earning males. Nevertheless, the relatively consistent finding of an upper-class bias among i-voters supports the hypothesis that the digital divide is, at least in part, responsible for the variation in the popularity of the online channel among different social groups.

However, most of the existing studies did not look at the special case of i-voting for expatriates. In this section, we extend the focus to this special segment of voters, tracing the profile of the typical expatriate internet voter. First, we discuss the only existing study we are aware of which centres upon expatriates (Serdült, 2010). Next we shift our focus to the 2011 federal elections and investigate the expatriate i-voter profile using data from an election survey targeted specifically at expatriates. We conclude with a short discussion.

\subsection{Evidence from the Expatriate Trials in Geneva}

In September 2009, Geneva began to experiment with i-voting for expatriates, thus becoming the second Swiss canton to do so (see Table 1). Serdült (2010) accompanied Geneva's first two experiments, both in 2009. Drawing on official voting records ${ }^{5}$, Serdült investigated some of the basic socio-demographic attributes of expatriate i-voters and compared them to those of expatriate postal voters (there were no expatriate ballot box voters). Table 2 reproduces his findings. First, male expatriates are slightly more likely to vote online; in both trials under consideration, the share of male $\mathrm{i}$-voters is between six and seven percentage points higher than the share of female $\mathrm{i}$ voters. Second, younger expatriates are more likely to use the online channel, though similarly to the residential context, it is not the very youngest but the 30-39 years cohort that made use of the opportunity most often. Finally, geography matters, with expatriates living in more distant places much more likely to vote online. In neighbouring France only about a third voted online, whereas around half of the expatriates living in Spain and close to two thirds of expatriates in the US voted online. Two mechanisms seem to explain this pattern. First, problems with postal delivery are likely to be lower the closer the country of residence is to Switzerland. Second, many of Geneva's Swiss abroad live just across the border in France and commute to Geneva on a daily basis. Since they can use Swiss post boxes to return their ballot (some of the border checkpoints are even equipped with drive-through post boxes), this group of expatriates does not face significant problems with postal delivery.

\footnotetext{
${ }^{5}$ Geneva is the only canton to maintain an official voting records database. Along with data on electoral participation, the database includes basic socio-demographic statistics (see Sciarini et al., 2013: 12).
} 
Table 2: Socio-demographic profile of Geneva's expatriate voters in the first two internet voting trials

\begin{tabular}{llcc}
\hline & Female & $\begin{array}{c}\text { September 2009 } \\
(N=2,121)\end{array}$ & $\begin{array}{c}\text { November 2009 } \\
(N=2,698)\end{array}$ \\
\hline Sex & Male & $30.2 \%$ & $31.9 \%$ \\
Age & $18-29$ & $36.7 \%$ & $38.2 \%$ \\
& $30-39$ & $40.7 \%$ & $38.3 \%$ \\
& $40-49$ & $50.9 \%$ & $50.8 \%$ \\
& $50-59$ & $43.2 \%$ & $42.1 \%$ \\
Country of residence & $60-69$ & $33.5 \%$ & $35.9 \%$ \\
(top 3) & $70-79$ & $23.1 \%$ & $26.1 \%$ \\
& $80+$ & $13.7 \%$ & $15.7 \%$ \\
& USA & $7.2 \%$ & $10.1 \%$ \\
& Spain & $63 \%$ & $57 \%$ \\
& France & $46 \%$ & $50 \%$ \\
\hline
\end{tabular}

Note: The table is reproduced from Serdült (2010). It shows the percentage of expatriate online voters among all expatriate remote voters (mail and internet) across three basic sociodemographic variables: sex, age and country of residence. The figures are based on Geneva's official voting records.

\subsection{Expatriate I-voters in the 2011 Federal Elections}

A major strength of Serdült's study is that it draws on official voting records and thus avoids any of the issues that arise when sampling from populations. However, this comes with a price: by its very nature, vote registry data covers only very basic socio-demographic statistics. Moreover, Serdült's study is naturally limited in time and space.

The expatriate study conducted in the context of the 2011 Swiss Election Study (Selects; Lutz, 2012) allows us to complement Serdült's findings with evidence from the 2011 federal elections. Besides extending the temporal and geographical scope, the use of election study data has the advantage in that it enables us to go beyond narrow socio-demographics such as age and gender. However, and this needs to be stressed, the 2011 expatriate survey is not representative of the expatriate population. Rather, it is a convenience sample, for two reasons. First, the survey does not sample from the entire expatriate voting population as respondents were contacted by e-mail and e-mail addresses were available for only half of the expatriates. Second, expatriates selfselected into the survey and the response rate was a mere 23 per cent. ${ }^{6}$ Hence, the results should be taken with care.

In the 2011 federal elections, expatriates from four cantons were able to vote online - Argovia, Basel-City, Grisons and St. Gallen (see Table 1). Many more cantons had already begun to offer ivoting for expatriates at the time, but technical as well as legal issues prohibited them from offering

Table 3: Profiling expatriate online voters in the 2011 Selects Swiss Abroad Study

\footnotetext{
${ }^{6}$ More specifically, the survey designers contacted a randomised sample of Swiss abroad who are registered to vote by e-mail and invited them to partake in an online survey. E-mail addresses were available for approximately every second expatriate registered to vote (Lutz, 2012). Note that expatriates who are not registered to vote were not sampled at all and these make up approximately $75 \%$ of all Swiss abroad. This plays no role here since we compare expatriate voters using the online channel to expatriate voters using the postal channel. Those not registered to vote are irrelevant since they cannot vote at all.
} 


\begin{tabular}{|c|c|c|c|c|c|c|}
\hline & & $n$ & I-voters & Other voters & Difference & $p$-value \\
\hline \multirow{5}{*}{ 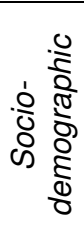 } & Age & 130 & 48.62 & 49.28 & -.65 & .83 \\
\hline & Female sex & 130 & .26 & .41 & -.16 & .1 \\
\hline & Education & 120 & 6.02 & 6.04 & -.02 & .97 \\
\hline & Married & 130 & .59 & .45 & .15 & .17 \\
\hline & Neighbour country & 130 & .3 & .52 & -.22 & .03 \\
\hline \multirow{4}{*}{$\begin{array}{l}\overline{\mathbb{S}} \\
\stackrel{0}{0} \\
0\end{array}$} & Party identification & 113 & 1.42 & 1.59 & -.17 & .27 \\
\hline & Political interest & 130 & 2.5 & 2.38 & .12 & .32 \\
\hline & Political knowledge & 130 & 2.1 & 1.55 & .55 & .02 \\
\hline & Left-right & 117 & 4.63 & 4.92 & -.28 & .64 \\
\hline
\end{tabular}

Note: This table compares expatriate voters who used the online channel to expatriate voters who voted using a different channel (mail or, if unlikely, ballot box). Only Swiss abroad who participated in the 2011 federal elections and had the possibility to cast their ballot via the internet are considered. The first column gives the number of observations, the second the means among internet voters, the third the means among other voters, the fourth the difference in means and the final column the statistical significance of the difference in means in two-sided t-tests. Sex, marital status and residence in a neighbour country are binaries. Age is measured in years and education on an eight-point variable. Party identification is measured on a three-point variable that ranges from "not close to any party" over "somewhat close to a party" to "close to a party". Political interest is measured on a four-point variable that ranges from "not interested at all" over "rather not interested" to "rather interested" and "very interested". Political knowledge is measured on a cumulative index indicating the number of correct answers to three political knowledge questions. Finally, a respondent's left-right position is measured via self-placement on an eleven-point scale with left $=0$ and right $=10$.

$\mathrm{i}$-voting for the elections. To learn about the profile of i-voters, we compare expatriate i-voters from these four cantons to expatriates from the same cantons who voted either by mail or, if somewhat unlikely, at polling places in Switzerland (the survey does not allow us to distinguish between the two). Expatriates registered in cantons which did not allow i-voting and expatriates located in countries that did not allow for data encryption (and could thus not vote online) are excluded. ${ }^{7}$ In total, our sample includes 130 expatriate voters, 101 of whom voted online.

In Table 3 we report the arithmetic means of a total of nine socio-demographic and political attributes, according to the voting channel and including two-sided t-tests to evaluate whether the differences are statistically significant. ${ }^{8}$ The table also gives some more details on operationalisations. The survey-based evidence appears to largely confirm the patterns Serdült found for Geneva. In particular, expatriates living in a country that borders Switzerland are statistically significantly less likely to use the online channel and therefore more likely to vote by mail. Also in line with Serdült, we find that men are more likely to use the electronic channel. The gender gap is substantial but (barely) misses conventional levels of statistical significance. This could be due to the combination of a relatively small $n$ with the small number of non-internet voters (29), which diminishes statistical power. The only surprising result is that age seems unrelated to the use of the online channel. It is possible that in the case of expatriates, the relatively large convenience associated with online voting is able to offset age effects. But this result may also be due to the survey's lack of representativity. Note that we found significant differences in the case of Geneva discussed above.

However as argued above, the election survey allows us to go beyond gender, age and country of residence. Specifically, the survey allows us to look at political variables and two further sociodemographics not covered by Serdült, marital status and education. In terms of the latter, we find that $\mathrm{i}$-voting - contrary to the residential context - appears to be education-neutral. Meanwhile

\footnotetext{
${ }^{7}$ A small number of respondents (12) indicated to have voted online even though this cannot be true.

${ }^{8}$ The results remain stable if instead of t-tests chi-square tests are used for binary attributes and Wilcoxon-MannWhitney rank sum tests for ordinal attributes.
} 
married expatriates appear overrepresented among i-voters - but this difference misses conventional levels of statistical significance. Turning to the political variables, we find that i-voters and non-i-voters do not differ significantly in terms of political interest or party identification. Furthermore, i-voting seems politically neutral given that i-voters are neither significantly more leftist nor rightist. The only significant difference that emerges is with regard to political knowledge, with i-voters having significantly higher knowledge.

\subsection{Discussion}

All in all, we find that the profile of expatriate $\mathrm{i}$-voters is rather similar to the profile of residential $\mathrm{i}$ voters. Our findings regarding age may be regarded as somewhat inconclusive given that only the voting records analysis suggests significant differences. However, given the selection bias in the expatriate survey, we should probably remain with the conclusion that expatriate $\mathrm{i}$-voters tend to be younger on average than other voters. At the same time, the finding that males are somewhat more likely to vote online seems to replicate in the case of the expatriates. And while we did not find significant differences with regard to education, we did with regard to political knowledge (which is somewhat similar). Finally, in line with most of the studies focusing on the residential context, no other political variable turned out to be significant; in particular, i-voting seems neutral with regard to political ideology. In conclusion, among expatriates, use of the online channel is likewise driven by the digital divide. The only finding that is specific to the expatriate case is that geography matters: increased distance to the home country makes an expatriate more likely to vote online.

It should be added that these findings are based on two single case studies. One of them even draws on a problematic, non-representative survey. Thus more and better evidence would be desirable. Moreover, some questions could not be answered with the evidence at hand. In particular, we would want to know whether the finding that the socio-demographic imbalances are largely caused by differences in internet access, tech-savviness and trust in the internet replicates for the expatriate case, as one would expect parting from a digital divide logic. Nonetheless, the evidence we have seems to suggest that the digital divide plays a role also in the expatriate case. We will have to wait and see whether the digital divide will, as some have suggested, indeed fade with the advancing internet penetration and as the young, tech-savvy generations grow older.

\section{Mobilisation Effect}

Proponents of internet voting are quick to argue that its introduction will benefit participation rates. The argument usually brought up in support is that internet voting makes the act of voting more convenient. Citizens are no longer obliged to show up at a specific place (the polling booth) at a specific time (election day), but can instead vote at whatever time suits them best over the course of up to several weeks before election day. They can even vote from the comfort of their home. Thus, the introduction of online voting reduces transaction costs and adds flexibility, thereby increasing the propensity to vote (Downs, 1957; Riker \& Ordeshook, 1968).

A positive effect on electoral mobilisation could be considered a particularly attractive feature of i-voting given the plummeting turnout rates in many established democracies (Lijphart, 1997). On the other hand, the digital divide logic would lead us to expect that an effect on mobilisation may be unequal, favouring the privileged and thus increasing the representational bias towards the upper classes (see the previous section as well as Alvarez \& Nagler, 2001 for example). It may not be necessary to worry about unequal mobilisation, however, as the existing evidence seems to speak against a mobilisation effect. Sure, there are studies in support of the mobilisation hypothesis (e.g. Alvarez et al., 2009; Trechsel \& Vassil, 2010; Vassil \& Weber, 2011; Goodman, 2014). Trechsel \& Vassil (2010), for instance, estimate that i-voting added between .3 and 2.6 percentage points to the total tally in four Estonian elections between 2005 and 2009. But studies in support of the mobilisation effect all draw on subjective impact measures and it is well-known that individuals are not the best judges of the causes of their own behaviour. On the other hand, studies with more rigid designs have invariably reported evidence against a mobilisation effect. Bochsler (2010), for 
example, shows that the i-voting mobilisation effect hinted at by Trechsel \& Vassil (2010) can largely be explained by increased electoral competition. Furthermore, in one of the most sophisticated analyses to date, Sciarini et al. (2013) conclude that i-voting did not have a discernible effect on electoral participation in the Swiss canton of Geneva.

At least in the Swiss case, this lack of evidence for an i-voting mobilisation effect should not come as a surprise: Switzerland ranks among the few countries with a fully generalised postal voting system. If a convenient voting mode (postal voting) is already available, the addition of a similarly convenient voting mode (internet voting) cannot decrease the cost of voting much further. Hence, it cannot have an effect on turnout either (contrary to postal voting, see Lüchinger et al., 2007).

Notably, however, this reasoning does not necessarily apply to the expatriate case. That is, good arguments for a mobilisation effect persist even if postal voting is available to expatriates, such as in the Swiss case where expatriates have been able to vote by mail since 1992 (Thurnherr \& Messerli, 2002). ${ }^{9}$ On the one hand, transaction costs decrease because expatriates no longer have to buy potentially expensive stamps to send their ballot back. On the other hand, and probably more importantly, online voting increases the certainty that a vote is also counted. With postal voting, it may take the ballot days or even weeks to reach its destination, a problem that is accentuated with increasing distance from the home country. Swiss municipalities often report expatriate ballots reaching them only after the election. This transmission problem becomes obsolete with i-voting since votes are immediately transmitted irrespective of geographical location. Therefore, compared to postal voting, i-voting can be expected to increase the benefit associated with voting because it increases the certainty that the vote is also counted. Parting from a rational choice logic (Downs, 1957; Riker \& Ordeshook, 1968), this can be expected to increase the propensity to vote.

From a theoretical perspective, there are thus good reasons to expect a mobilisation effect at least in the case of expatriates. Aside from suggestive evidence in that direction (Lutz, 2012) this argument has not yet been empirically tested. In the remainder of this section, we present the first empirical study of the i-voting mobilisation effect among expatriates. First, we discuss data and methods. We then present the results, including a series of robustness tests and conclude with a short discussion.

\subsection{Research Design}

In aggregate-level studies of electoral mobilisation such as this one, the measurement of the dependent variable typically does not need much discussion. ${ }^{10}$ In the present case however, we are interested in turnout among a particular segment of voters: expatriates. Unfortunately, most cantons do not separately record turnout among this group of voters. ${ }^{11}$ Thus, testing directly for whether the introduction of internet voting had an effect on turnout among expatriates is not possible. Yet it is still possible to come up with a measure of electoral mobilisation among expatriates. Contrary to Swiss residents, expatriates are not automatically registered on the electoral roll, but rather have to register with their local embassy or consulate. Registration rates

\footnotetext{
${ }^{9}$ The mobilisation potential would be highest in situations where expatriates cannot vote by post, but have to vote at the nearest consulate. The next consulate may be hundreds or even thousands of kilometers away, implying a very substantial cost reduction if $\mathrm{i}$-voting is introduced.

${ }^{10}$ In aggregate-level studies, turnout figures are the obvious means to measure electoral mobilisation. On the other hand, there are various ways of measuring electoral mobilisation in individual-level studies: actual voting records, asking respondents about their intention to vote before an election and asking respondents whether they voted after the election.

${ }^{11}$ Only five cantons provide reasonably long time-series of turnout among expatriates (Appenzell I. R., Basel-City, Geneva, Lucerne, and Vaud). Recently, more cantons have started to record the expatriate turnout. But in most cases, the records start either shortly before the introduction of i-voting (e.g. Argovia) or shortly after the introduction of i-voting (e.g. Berne). For obvious reasons, this does not offer much for an evaluation of the effect of online voting. A second problem is that even if turnout data is available, the expatriate turnout is always calculated as the percentage of registered expatriates.
} 
have increased over the past few years, but as of 2013 , still only approximately one in four expatriates were registered. If an expatriate does not register, they will not be sent voting materials and consequently cannot vote. Registration rates can thus be interpreted as a measure of electoral mobilisation. Note, however, that registration does not necessarily imply electoral participation. From the few places where such data exists, we know that on average only about four in ten of those expatriates who registered actually turn out to vote. Thus, it has to be kept in mind that we are looking at a rather specific element of electoral mobilisation.

Data on the expatriates' registration rate is more readily available: every year, the Swiss government issues a report including the total (worldwide) number of expatriates eligible to vote as well as the number who registered to vote in elections and referendums. What the government does not issue, however, is the registration rate by canton. ${ }^{12}$ Unfortunately, this means that a natural testing ground for the mobilisation hypothesis is lost: we cannot compare registration rates between cantons which have introduced i-voting and cantons which have not introduced i-voting. We need to be yet a bit more creative about the research design.

As mentioned above, there was a rule (abandoned in 2013) that only expatriates from countries which allow for data encryption could vote online. ${ }^{13}$ Thus, even if a canton introduced internet voting, it was available to only a portion of its expatriates. For instance, while an expatriate living in the United States could i-vote, an expatriate living in Brazil could not. Most expatriates still profited from the roll-out, as almost $90 \%$ of expatriates live in a country that allows for data encryption. Nevertheless, the introduction of internet voting in ever more cantons from 2008 onwards could only have an impact in countries that allow for data encryption. ${ }^{14}$ Thus, it is possible to identify the effect of i-voting on registration rates by comparing rates in different countries. Fortunately, data on the registration rate by country of residence is available.

Following the above logic, the simplest method to identify the mobilisation effect would involve a simple comparison of the registration rates between countries that allow for data encryption and those that do not allow for data encryption. However, registration rates may vary for reasons other than the introduction of $i$-voting. In particular, the structural composition of expatriate populations is likely to vary; for example, some countries may attract more post-retirement emigration (e.g. Thailand) while others may have more student and work-related migration (e.g. France). It is quite likely that variation in the structural composition in terms of age, education and income affects registration rates. Hence, raw comparisons are likely to be biased due to confounders. Credible causal inference requires us to identify credible counterfactuals (Holland, 1986).

To counter confounding, we employ a difference-in-differences design (Ashenfelter, 1978; Card \& Krueger, 1994; Angrist \& Pischke, 2009). Difference-in-differences designs have become immensely popular in policy or programme evaluations, in particular in evaluations of the mobilisation potential of convenience voting reforms (e.g. Gerber et al., 2013; Lüchinger et al., 2007). The crucial advantage of a difference-in-differences design is that it eliminates all possible unit-level confounders, that is, all possible confounding due to time-invariant differences between the expatriate populations in different countries. At the same time, the difference-in-differences method eliminates all possible confounding due to 'common shocks', that is, bias due to any event that may simultaneously affect registration rates in all countries. The basic logic of a difference-indifference design is to exploit longitudinal variation in both the treatment and outcome, whereby the causal effect is identified as the treated-control difference after treatment adjusted by the treatedcontrol difference before treatment. This means that the effect of $\mathrm{i}$-voting is identified as the difference in the registration rates between countries in which $\mathrm{i}$-voting is possible and countries in

\footnotetext{
${ }^{12}$ Despite repeated requests, the Swiss government did not make that data available to us.

${ }^{13}$ These are mostly European states, in particular EU member states, and some highly developed overseas countries including the United States, Mexico and Canada.

${ }^{14}$ It must be clear that even in countries that allow for data encryption, not all expatriates would typically have access to i-voting as not all cantons offer i-voting.
} 
which i-voting is not possible after the switch to $i$-voting minus the difference in registration rates between countries in which i-voting is possible and countries in which i-voting is not possible before the switch. The data set we have collected allows for such a comparison as it tracks registration rates in all countries with an expatriate population both before and after the first canton, Neuchâtel, introduced i-voting in 2008 (it covers 2001 to 2013).

Of course, causal inference based on difference-in-differences does not come without assumptions. In this case the key identification assumption is what is called the parallel trends or parallel paths assumption. This requires that in the absence of treatment, treated and control groups would follow a parallel path (Keele \& Minozzi, 2013). In other words, had there not been ivoting, registration rates in countries in which i-voting was possible and registration rates in which i-voting was not possible should have developed in parallel. Since this cannot be observed, this assumption cannot be directly tested. However, we provide informal evidence supporting the plausibility of the identification assumption further below.

We estimate the difference-in-differences with the following two-way fixed effects model:

$$
\text { Reg rate }_{i j}=\beta_{0}+\beta_{1} \text { Ivote }_{i j}+u_{i}+v_{j}+\varepsilon_{i j}
$$

where $\operatorname{Reg}_{\text {rate }}$ ij is the registration rate in country $i$ in year $j, \beta_{0}$ a constant, $u_{i}$ denotes a canton fixed effect that controls for time-invariant, country-specific unobserved confounders, $v_{j}$ a year fixed effect that controls for common, year-specific shocks, and $\varepsilon_{i j}$ a country-year-specific idiosyncratic error term. Ivote ${ }_{i j}$ is a dummy that takes the value 1 in countries that allow for data encryption (where i-voting was thus available) from 2008 onwards, the year the first canton (Neuchâtel) extended $\mathrm{i}$-voting to its expatriates and 0 otherwise. $\beta_{1}$ captures the effect of the availability of $\mathrm{i}$ voting and is thus the parameter of interest. Given that our outcome of interest (registration rates) has metric measurement level and is reasonably close to normally distributed, this model can be fitted using standard ordinary least squares (OLS). Since we observe the same countries over time, it is likely that the errors are serially correlated within countries, which can lead to over-optimistic conclusions about statistical uncertainty. Thus we follow Bertrand et al. (2004) and cluster the standard errors at the country level.

\subsection{Results}

Table 4 presents the difference-in-differences estimates. The first column gives the results from our main model as described above. According to this model, the introduction of $\mathrm{i}$-voting did not have an effect on the number of registered expatriates that is statistically distinguishable from zero at conventional levels. Note that we excluded all countries with an expatriate population of less than 500. Small numbers make the registration rates bounce a lot, which renders the parallel trends assumption unreasonable (we test the robustness to alternative thresholds below). For a similar reason, we excluded China and Singapore - the trajectories in these two countries are highly deviant (below we also show the results of a model including these two countries). ${ }^{15}$

The key identification assumption in difference-in-differences designs is that the outcomes would have followed parallel trends in the absence of treatment (see above). While this assumption cannot be directly tested, it is possible to investigate whether the treatment and control group followed a parallel trend before the treatment application. If the two trends are largely parallel, we have informal evidence that the identifying assumption holds (Angrist \& Pischke, 2009; Keele \& Minozzi, 2012). In Figure 4, we plot the mean rate in countries which allow for data encryption

\footnotetext{
${ }^{15}$ Of the 47 countries fulfilling these criteria, 28 are in the treatment group (where i-voting was possible after 2008) and 19 in the control group (where i-voting was not possible throughout).
} 
Table 4: Difference-in-differences estimates

\begin{tabular}{|c|c|c|c|c|c|c|}
\hline & (1) & (2) & (3) & (4) & (5) & (6) \\
\hline & Main model & $\begin{array}{l}\text { Two-way } \\
\text { clustering }\end{array}$ & $\begin{array}{l}\text { Time } \\
\text { trends }\end{array}$ & $\begin{array}{l}\text { China } \\
\text { \& Singapore } \\
\text { added }\end{array}$ & $\begin{array}{l}>200 \\
\text { expats per } \\
\text { cluster }\end{array}$ & $\begin{array}{l}>1,000 \\
\text { expats per } \\
\text { cluster }\end{array}$ \\
\hline I-voting availability & $\begin{array}{l}-.36 \\
(.9)\end{array}$ & $\begin{array}{l}-.36 \\
(.9)\end{array}$ & $\begin{array}{l}-.48 \\
(.34)\end{array}$ & $\begin{array}{c}-1.25 \\
(1.05)\end{array}$ & $\begin{array}{c}-.88 \\
(.84)\end{array}$ & $\begin{array}{c}-.67 \\
(1.28)\end{array}$ \\
\hline $\mathrm{N}$ & 611 & 611 & 611 & 637 & 858 & 390 \\
\hline Countries & 47 & 47 & 47 & 49 & 66 & 30 \\
\hline Country fixed effects & $\checkmark$ & $\checkmark$ & $\checkmark$ & $\checkmark$ & $\checkmark$ & $\checkmark$ \\
\hline Year fixed effects & $\checkmark$ & $\checkmark$ & $\checkmark$ & $\checkmark$ & $\checkmark$ & $\checkmark$ \\
\hline One-way clustered standard errors & $\checkmark$ & $x$ & $\checkmark$ & $\checkmark$ & $\checkmark$ & $\checkmark$ \\
\hline Two-way clustered standard errors & $x$ & $\checkmark$ & $x$ & $x$ & $x$ & $x$ \\
\hline Country-specific linear time trends & $x$ & $x$ & $\checkmark$ & $x$ & $x$ & $x$ \\
\hline
\end{tabular}

Note: This table shows the coefficients from two-way fixed effects regressions of the expatriates' registration rate on the availability of $i$-voting with standard errors in brackets. ${ }^{*} p<.1,{ }^{* *} p<.05,{ }^{* * *} p<.01$.

(where i-voting was possible) and countries which do not allow for data encryption (where i-voting was not possible). Again, we exclude countries with less than 500 expatriates as well as China and Singapore. The resulting plot suggests that the trends in the two groups are indeed close to parallel before the first canton, Neuchâtel, introduced i-voting in 2008. Hence, based on Figure 4, the identification assumption seems credible. Moreover, Figure 4 nicely illustrates our finding of no effect: the trends in the two groups remain close to parallel after 2008.

In columns 2 to 6 of Table 4, we report the results of a series of robustness tests. Specifically, in column 2 we cluster the standard errors on both the country and the year-level, thus countering the potential threat for the variability estimate due to possible contemporaneous dependence (Cameron et al. 2011). In column 3 we add unit-specific linear time trends. This weakens the parallel trends assumption since it controls for smooth trends at the country level. In column 4 we add China and Singapore and in columns 5 and 6 we report the results of models with either a lower or higher threshold for the minimum cluster size, respectively (i.e. with more/less countries and fewer/more observations by cluster). Reassuringly, the result remains the same irrespective of the specification.

\subsection{Discussion}

Exploiting the fact that some countries were excluded from the internet voting roll-out until the end of 2013, this section showed that there was no disproportionate increase in registration rates in countries where i-voting was possible. Our analysis thus points to the conclusion that the increase in registration rates we observed in the last few years has nothing to do with the introduction of $\mathrm{i}$ voting.

Our finding may come as a disappointment for proponents of i-voting. On the other hand, it might reassure those who fear that online voting leads to further increases in the representation gap between the rich and the poor. It might also reassure those who tend to be sceptical about the expatriates' say over the matters of their home country. However, it is important to reiterate that registration is not the same as participation. And it is possible that the introduction of i-voting had an effect on turnout, but not on the registration rate. An argument in support of such a contention is that those not registered are generally less involved with the home country and may thus not (yet) know about the possibility to vote online - contrary to those already registered. Unfortunately, data limitations precluded us from testing the effect on actual turnout rates among expatriates. Thus, our answer to the question whether i-voting increased electoral mobilisation among expatriates can only be a partial one. 


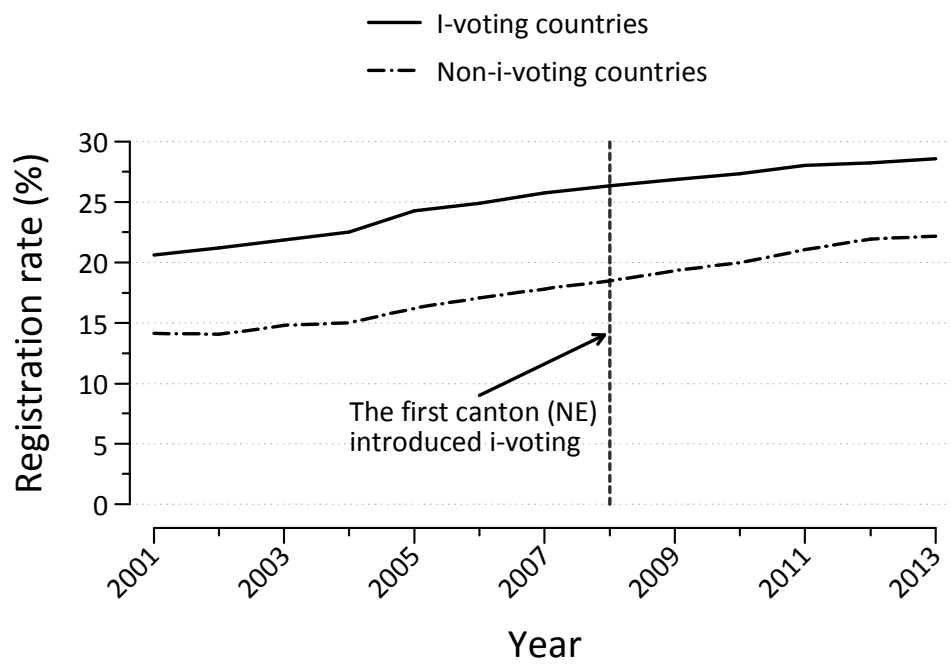

Figure 4: Registration rates by i-voting availability

\section{Conclusion}

In June 2008 the first canton made i-voting available to its expatriates. Other cantons quickly followed and as of today, expatriates from 12 cantons can cast their vote online. Focusing on the recent extension of Switzerland's i-voting roll-out to expatriates, this paper investigated three questions at the core of the internet voting research agenda: i-voting's popularity, the profile of online voters and its mobilisation potential.

Our findings indicate that i-voting has been very well received by Switzerland's expatriates. With the exception of Neuchâtel and Geneva, the online channel has already become the expatriates' preferred mode of voting where it is available. Moreover, expatriates who tested the new channel seem to remain loyal to it. Finally, there is an upward trend in usage, even if there are some signs that this trend is slowing down. This is in contrast to the much lower usage rates in the trials involving Swiss residents and also in the trials in countries like Estonia and Canada.

Leaving aside i-voting's comparatively high popularity, familiar patterns seem to replicate in the expatriate trials. First, expatriate i-voters tend to be young, male and upper-class. Thus, use of the online channel seems driven by the digital divide, similarly to the residential context. The only factor that is specific to expatriates is that expatriates in more distant places appear more likely to vote online, presumably because of problems with postal delivery. Second, $i$-voting appears not to affect electoral mobilisation among expatriates, similarly to other trials. However, for reasons of data (un-) availability, we had to focus on registration rates and could not consider actual turnout rates. Thus, this finding comes with a caveat: since registration is not the same as participation, it is possible that the introduction of $\mathrm{i}$-voting had an effect on turnout among expatriates, but not the registration rate. Moreover, it could be that the effect has yet to kick in, for example, because many expatriates are not yet aware of the possibility to cast their vote online. If not, this will at least reassure those who fear that i-voting will necessarily lead to unequal mobilisation (e.g. Alvarez \& Nagler, 2001) as well as those who are sceptical about the expatriates' say over matters of their home country.

Despite the persistence of the digital divide and the potential lack of a mobilisation effect, the expatriate trials can still be considered a success story, at least from the perspective of the advocates of a general introduction of i-voting in Switzerland. Contrary to the residents' trials, the expatriate trials proved to be basically uncontested. The generally beneficial experience and high usage rates in particular have helped create a positive story paving the way for the further 
development and generalisation of the online channel. In 2015, the transition to the secondgeneration i-voting systems is set to begin, which will make online voting more secure and add to verifiability. More cantons are preparing to offer i-voting to expatriates for the federal elections in October 2015 and, in what will become the third phase in the Swiss roll-out, four non-pilot cantons (Argovia, Grisons, Solothurn and Thurgau) will begin with trials involving residents in 2016. Thus, Switzerland is set to continue on its piecemeal road to internet voting, moving closer to a possible general introduction.

\section{References}

Alvarez, M. R., \& Nagler, J. (2001). The Likely Consequences of Internet Voting for Political Representation. Loyola of Los Angeles Law Review, 34(3): 1139-1141.

Alvarez, R. M., \& Hall, T. E., \& Trechsel, A. H. (2009). Internet Voting in Comparative Perspective: The Case of Estonia. PS: Political Science and Politics, 42(3): 497-505.

Angrist, J. D., \& Pischke, J. (2009). Mostly Harmless Econometrics. An Empiricist's Companion. Princeton, NJ: Princeton University Press.

Ashenfelter, O. (1978), Estimating the Effect of Training Programs on Earnings. Review of Economics and Statistics, 60(1): 47-57.

Bergh, J., \& Christensen, D. A. (2012). Valgdeltakelse og bruk av Internettstemmegivning. Har hvordan velgerne stemmer betydning for om de stemmer?" In S. Bock Segaard, \& J. Saglie (Eds.), Evaluering av forsøket med e-valg 2011 (pp. 29-157). Oslo: Institutt for Samfunnsforskning.

Bertrand, M., Duflo, E., \& Sendhil, M. (2004). How Much Should We Trust Differences-In-Differences Estimates? Quarterly Journal of Economics, 119(1):249-275.

Bochsler, D. (2010). Can Internet Voting Increase Political Participation? Remote Electronic Voting and Turnout in the 2007 Parliamentary Elections. Paper presented at the 'Internet and Voting' conference, June 3-4, 2010, Fiesole, Italy.

Cameron, C. A., Gelbach, J. B., \& Miller, D. L. (2011). Robust Inference with Multiway Clustering. Journal of Business \& Economic Statistics, 29(2): 238-249.

Card, D., \& Krueger, A. (1994). Minimum Wages and Employment: A Case Study of the Fast Food Industry in New Jersey and Pennsylvania. American Economic Review, 84(4): 772-784.

Christin, T., \& Trechsel, A. H. (2005). Analyse du scrutin du 26 septembre 2004 dans quatre communes genevoises (Anières, Carouge, Cologny et Meyrin). Geneva : E-Democracy Centre, University of Geneva.

Downs, A. (1957). An Economic Theory of Political Action in a Democracy. New York, NY: Harper \& Row.

Driza-Maurer, A. (2013). Internet Voting and Federalism: The Swiss Case. Revista General de Derecho Publico Comparado, 13(1): 1-33.

Driza-Maurer, A., Spycher, O., Taglioni, G., \& Weber, A. (2012). E-voting for Swiss Abroad: A Joint Project between the Confederation and the Cantons. In M. J. Kripp, M. Volkamer, \& R. Grimm (Eds.), Electronic Voting 2012. Proceedings of the 5th Conference on Electronic Voting 2012 (EVOTE2012) (pp. 173-187). Bonn: Ges. für Informatik.

Gerber, A. S., Huber, G. A., \& Hill, S. J. (2013). Identifying the Effect of All-mail Elections on Turnout: Staggered Reform in the Evergreen State. Political Science Research and Methods 1(1): 91-116.

Gerlach, J., \& Gasser, U. (2009). Three Case Studies from Switzerland: E-voting. Berkman Center Research Publication, 3(1): $1-17$.

Germann, M., Conradin, F., Wellig, C., \& Serdült, U. (2014). Five Years of Internet Voting for Swiss Expatriates. In P. Parycek, \& N. Edelmann (Eds.), CeDEM 14. Conference for E-Democracy and Open Government. 21-23 May 2014, Danube University Krems, Austria (pp. 127-140). Krems: Danube University Krems.

Goodman, N. J. (2014). Internet Voting in a Local Election in Canada. In B. Grofman, A. H. Trechsel, \& M. Franklin (Eds.), The Internet and Democracy in Global Perspective. Voters, Candidates, Parties, and Social Movements (pp. 7-24). Heidelberg: Springer.

Henry, S. (2003). Can Remote Internet Voting Increase Turnout? Journal of Information Management, 55(4): $193-202$.

Holland, P. W. (1986). Statistics and Causal Inference. Journal of the American Statistical Association 81(396): 945-960.

Keele, L., \& Minozzi, W. (2013). How Much Is Minnesota like Wisconsin? Assumptions and Counterfactuals in Causal Inference with Observational Data. Political Analysis, 21(2): 193-216.

Kersting, N., \& Baldersheim, H. (Eds.) (2004). Electronic Voting and Democracy: A Comparative Analysis. Basingstoke: Palgrave Macmillan. 
Lijphart, A. (1997). Unequal Participation: Democracy's Unresolved Dilemma. American Political Science Review, 91(1): 114.

Lüchinger, S., Rosinger, M., \& Stutzer, A. (2007). The Impact of Postal Voting on Participation: Evidence from Switzerland. Swiss Political Science Review, 13(2): 167-202.

Lutz, G. (2012). Eidgenössische Wahlen 2011: Wahlteilnahme und Wahlentscheid. Lausanne: Selects-FORS.

Mendez, F. (2010). Elections and the Internet: On the Difficulties of 'Upgrading' Elections in the Digital Era. Representation, 46(4): 459-469.

Mendez, F., \& Serdült, U. (2014). From Initial Idea to Piecemeal Implementation: Switzerland's First Decade of Internet Voting Reviewed. In D. Zissis, \& D. Lekkas (Eds.), Design, Development, and Use of Secure Electronic Voting Systems (pp. 115-127). Hershey, PA: IGI Global.

Mendez, F., Serdült, U., \& Wheatley, J. (2014). The Growth of Mechanisms of E-Governance and E-Democracy in Europe: An Overview. Paper presented at the conference "Smart City: Social Participation and Urban Governance International Conference", June 5-7, 2014, Shanghai, China.

Norris, P. (2001). Digital Divide: Civic Engagement, Information Poverty, and the Internet Worldwide. Cambridge: Cambridge University Press.

Pammett, J. H., \& Goodman, N. (2013). Consultation and Evaluation Practices in the Implementation of Internet Voting in Canada and Europe. Ottawa: Canada-Europe Transatlantic Dialogue, Carleton University.

Portenier, A., Germann, M., \& Serdült, U. (2014). Sozio-ökonomische Zusammensetzung der e-voter. Retrieved September 29, 2013, from http://www.ivotingproject.com/

Riker, William H., \& Ordeshook, P. C. (1968). A Theory of the Calculus of Voting. American Political Science Review, 62(1): 25-42.

Sciarini, P., Cappelletti, F., Goldberg, A., Nai, A., \& Tawfik, A. (2013). Étude du vote par Internet dans le canton de Genève. Geneva: University of Geneva.

Serdült, U. (2010). Internet Voting for the Swiss Abroad of Geneva: First Online Survey Results. In J. L. Chappelet, O. Glassey, M. Janssen, A. Macintosh, J. Scholl, E. Tambouris, \& M. Wimmer (Eds.), Electronic Government and Electronic Participation: Joint Proceedings of Ongoing Research and Projects of IFIP EGOV and ePart 2010 (pp. 319325). Linz: Trauner.

Serdült, U. (2014). Switzerland. In M. Qvortrup (Ed.), Referendums around the World: The Continued Growth of Direct Democracy (pp. 65-121). Basingstoke: Palgrave Macmillan.

Serdült, U., \& Trechsel, A. H. (2006). Umfrage bei Stimmberechtigten der Zürcher Gemeinden Bertschikon, Bülach und Schlieren anlässlich des Pilotversuchs zum Vote électronique vom 27. November 2005. Bern: Sektion politische Rechte, Bundeskanzlei.

Thurnherr, W., \& Messerli, P. (2002). Auslandschweizerpolitik des Bundes nach dem Zweiten Weltkrieg. Schweizerisches Bundesarchiv: Studien und Quellen, 28: 65-86.

Trechsel, A. H., \& Mendez, F. (Eds.) (2005). The European Union and E-Voting: Addressing the European Parliament's Internet Voting Challenge. London: Routledge.

Trechsel, A. H., \& Vassil, K. (2010). Internet Voting in Estonia. A Comparative Analysis of Four Elections since 2005. Report for the Council of Europe. Florence: Robert Schuman Centre for Advanced Studies, European University Institute.

Trechsel, A. H., \& Vassil, K. (2011). Internet Voting in Estonia. A Comparative Analysis of Five Elections since 2005. Report for the Estonian National Electoral Committee. Florence: Robert Schuman Centre for Advanced Studies, European University Institute.

Vassil, K., \& Weber, T. (2011). A Bottleneck Model of E-Voting: Why Technology Fails to Boost Turnout. New Media Society, 13(8): 1336-1354.

\section{About the Authors}

\section{Micha Germann}

Micha Germann is a PhD researcher at the Centre for Democracy Studies (ZDA) at the University of Zurich and the Centre for Comparative and International Studies at ETH Zurich. His research interests include self-determination conflicts, direct democracy, internet voting, and voting advice applications (VAAs).

Uwe Serdült

Uwe Serdült is Vice-director of the Centre for Research on Direct Democracy (c2d) in the Centre for Democracy Studies Aarau (ZDA) at the University of Zurich. Before coming to Aarau he taught and worked as a post-doctoral researcher at the Universities of Zurich and Geneva. 